\title{
Recomendaciones a los cuerpos directivos de las agrupaciones médicas en su relación con la industria
}

\author{
Antonio Soda, Carlos Campillo, Oscar Arrieta, Rubén Burgos, Miguel Ángel Celis, Manuel De la Llata, \\ Judith Domínguez, José Halabe, Sergio Islas, Luis Jasso, Alberto Lifshitz, Mucio Moreno, Ricardo \\ Plancarte, Alejandro Reyes, Guillermo J. Ruiz-Argüelles, Emma Verástegui y Julio Sotelo \\ Comité de Ética y Transparencia en la Relación Médico-Industria, Academia Nacional de Medicina, Ciudad de México, México
}

\begin{abstract}
Resumen
Las actividades de educación médica continua con frecuencia son apoyadas financieramente por la industria farmacéutica y de implementos médicos. Con el propósito de velar por la ética y rendición de cuentas en el manejo de estos apoyos, en el presente texto el Comité de Ética y Transparencia en la Relación Médico-Industria (Cetremi) de la Academia Nacional de Medicina de México formula recomendaciones a los directivos de agrupaciones médicas.
\end{abstract}

PALABRAS CLAVE: Patrocinio de eventos médicos. Industria farmacéutica. Donativos.

\begin{abstract}
Continuing medical education activities are often financially supported by pharmaceutical and device companies. With the purpose to ensure ethics and accountability in the management of this assistance, the Committee of Ethics and Transparency in the Physician-Industry Relationship of the National Academy of Medicine of Mexico formulates recommendations to medical associations' leaders in this text.
\end{abstract}

KEY WORDS: Sponsoring of medical events. Pharmaceutical industry. Donations

Los cuerpos directivos de las agrupaciones médicas (colegios médicos, asociaciones, academias, sociedades médicas, etcétera) están encargados de tratar con la industria (tanto farmacéutica, como industrias innovadoras de dispositivos médicos y sistemas de diagnóstico, industria turística, de transportación, entre otras), el potencial financiamiento de educación médica continua y la promoción de sus productos durante reuniones académicas. Se trata de una gran responsabilidad porque lo hacen en representación de sus agremiados. Eso los obliga a observar una actitud intachable para evitar suspicacias y malas interpretaciones, que surgen cuando se tratan asuntos económicos. No son autónomos, se deben a sus representados, con los cuales adquieren el compromiso de informar acerca de sus actividades, evitar conflictos de interés y no anteponer intereses particulares sobre los de los asociados, lo que contribuirá al fortalecimiento de una buena imagen de la asociación que representan. Una actitud que despierte sospechas puede empañar esa imagen, sobre todo en tiempos recientes que algunos sectores de la sociedad han manifestado inquietud por posibles acuerdos indebidos entre el gremio médico y la industria.

Para cumplir con su responsabilidad y evitar suspicacias en su relación financiera con la Industria, los cuerpos directivos de las asociaciones médicas, además de observar una conducta que no se aparte de los principios éticos fundamentales de la profesión médica, deben actuar con transparencia e informar a sus agremiados sobre sus acciones.
Correspondencia:

Julio Sotelo

E-mail: jsotelo@unam.mx
Fecha de recepción: 05-09-2018

Fecha de aceptación: 13-09-2018

DOI: 10.24875/GMM.18004653
Gac Med Mex. 2018;154:622-623

Disponible en PubMed

www.gacetamedicademexico.com 
Con el fin de salvaguardar la imagen del gremio médico y coadyuvar con los cuerpos directivos de las asociaciones médicas a que demuestren que en su relación financiera con la industria actúan con transparencia y que sus acciones cuentan con el respaldo de sus agremiados, el Comité de Ética y Transparencia en la Relación Médico-Industria (Cetremi) de la Academia Nacional de Medicina emite las siguientes recomendaciones:

1. Actuar cuidando la buena imagen de la profesión médica, evitando conflictos de interés que la pongan en riesgo. Recordar que no actúan a título personal, sino que son interlocutores de sus agremiados y deben cumplir fundamentalmente con los preceptos académicos y los estatutos de sus agrupaciones.

2. La relación con la industria farmacéutica debe ser voluntaria. No hay obligación de participar y se interrumpe sin consecuencias en caso de no llegar a acuerdos.

3. Los programas académicos deben tener autonomía y ningún sesgo promocional de manipulación comercial; toda participación deberá tener como valor supremo el beneficio de los pacientes.

4. No deben inducir a los agremiados a prescribir o no algún medicamento o insumo y deben evitar que la industria lo haga.
5. Deben informar con detalle a sus agremiados de las gestiones y apoyos de la industria, especificando la cantidad recibida y su destino.

6. Cuando los apoyos recibidos sean para actividades académicas deben destinarse para ese propósito y desglosar ante sus agremiados con detalle cómo se gastaron.

7. Cuando los apoyos sean para actividades de promoción (por ejemplo, ventas de espacios en exposiciones o simposios patrocinados), los directivos deben informar a sus agremiados la cantidad recibida y su destino.

8. Los directivos deben informar a sus agremiados la lista de beneficios que la industria otorga en forma de becas (transporte, cuotas de inscripción al evento, alimentación), ya sea de manera directa a los asistentes o a los directivos. En el primer caso, los directivos solicitarán a la industria la lista de becarios.

9. Los directivos deben informar a sus agremiados sobre los apoyos personales (cuotas a congresos internacionales, viajes, honorarios por participación académica) que reciban de la industria.

10. Los directivos deben contar con documentos comprobatorios de que informaron a sus agremiados sobre apoyos recibidos por parte de la industria y los mostrarán cuando les sean requeridos por alguna institución médica con autoridad moral representativa. 